\title{
THE USE OF SURVIVAL TIME IN THE ANALYSIS OF NEUTRALIZATION TESTS FOR SERUM ANTIBODY SURVEYS
}

\author{
BY C. E. GORDON SMITH \\ Virus Research Officer, Institute for Medical Research \\ Kuala Lumpur, Malaya \\ AND D. R. WESTGARTH \\ Senior Statistician, Rubber Research Institute, \\ Kuala Lumpur, Malaya
}

(With 2 Figures in the Text)

When carrying out surveys of human and animal sera for the presence of antibodies to the arthropod-borne neurotropic viruses, the neutralization test in mice is by far the most specific test available. This test is, however, expensive and timeconsuming; in order to test a large number of sera economically only a few animals can be used for each serum, and repetition of tests must be avoided as much as possible. Because the exact dose of virus which will be present in a test cannot be predicted, comparison of tests done on different days is unreliable by current methods of analysis, which are based on mortality ratios only. By making use of additional information available, however, namely the survival times of the mice, a method of analysis has been devised which enables comparisons to be made between tests involving widely different doses of virus.

\section{(1) PREVIOUS METHODS}

The use of serum neutralization tests in mice for large numbers of sera seems to have stemmed from the need to examine populations for antibodies to yellow fever in an attempt to delineate the geographical and zoological distribution of that disease. In the last five or six years, survey neutralization tests have been used on a very large scale, especially by workers of the Rockefeller Foundation who are trying to map out the geographical distribution in man of antibodies to the arthropod-borne viruses which were isolated by workers of the Foundation between 1937 and 1948, mainly in Africa. Much very valuable and interesting information has emerged from this work (e.g. Smithburn, Taylor, Rizk \& Kader, 1954a; Smithburn, Kerr \& Gatne, 1954b).

\section{$(1 \cdot 1)$ Basic principles of previous methods}

The more important techniques were reviewed by Bugher (1948), but many other modifications in detail have been used. Fundamentally, however, all such techniques depend on roughly the following sequence of events:

Preparation of seed virus. This is usually a $20 \%$ suspension in non-immune serum of brains of moribund mice, centrifuged to remove large particles. 
Assay of seed virus. Tenfold serial dilutions of seed virus are inoculated into groups of mice and the $\mathrm{LD}_{50}$ end-point is calculated by one of a number of methods (Reed \& Muench, 1938; Finney, 1952, etc.). We prefer a simple graphical technique in which the probit of the percentage mortality in each group of mice is plotted against the logarithm of corresponding dose of virus. A straight line is fitted by eye to the observations and the log dose at which the line cuts probit 5 is the $\mathrm{LD}_{50}$ titre. This method has the advantage (over, say, that of Reed \& Muench) of being applicable to irregularly spaced virus dilutions and to variously sized groups of mice, and it does not involve cumulative mortality totals which are so readily abused. An additional advantage is that there is an easy method of estimating the confidence limits of the $\mathrm{LD}_{50}$ titre thus obtained (Miller \& Tainter, 1944).

Storage of seed virus. Seed virus must be stored for at least the $2-3$ weeks necessary for its assay. Freeze drying is best, but storage in sealed glass ampoules at about $-70^{\circ} \mathrm{C}$. on dry ice is more usual. Samples for assay are taken from seed virus stored either lyophilized or frozen. Most viruses lose titre during storage, most rapidly in the early stages. In this laboratory it has been found that some viruses store better than others, e.g. Japanese encephalitis virus (JE) and French neurotropic yellow fever virus (FNYF) retain a high titre for many months, while the dengue viruses may drop tenfold or a 100 -fold in titre within a few weeks.

The test. When the $\mathrm{LD}_{50}$ titre of the seed virus has been determined, a dose of virus (usually $100 \mathrm{LD}_{50}$ ) is chosen and the undiluted sera to be tested are mixed with it and incubated. These serum-virus mixtures are then inoculated each into a group of six mice. The actual amount of virus used in the test is estimated by dilution titration (as above) at the beginning and end of the experiment.

After an appropriate number of days of observation (e.g. 14 for JE and FNYF; 21 for dengue) the mice still surviving are discarded. For each serum-virus mixture the mortality ratio in the group of mice inoculated is calculated. For this purpose mice dying before (say) the 4th day are disregarded as having probably died traumatic deaths, and mice paralysed on the day of discard are considered to have died. Arbitrary ratios are defined as positive (if $0 / 6,1 / 6,0 / 5,1 / 5$, die), negative (if $6 / 6,5 / 6,4 / 6,5 / 5,4 / 5$, die), and equivocal (all other ratios) (Smithburn et al., $1954 b)$.

\section{(1-2) Reasons for rejection of this type of test}

Difficulties in achieving the desired dose of virus. Smithburn (1954) and Smithburn et al. $(1954 a, b)$ with a wide experience and excellent facilities, intending to use $100 \mathrm{LD}_{50}$ in 163 tests, found that they had actually used the following range of doses (compiled by summing the results in the three papers):

$\begin{array}{lcc}\text { Dose }\left(\mathrm{LD}_{50}\right) & \text { No. of tests } & \begin{array}{c}\text { Percentage } \\ \text { of tests }\end{array} \\ \text { Under } 50 & 22 & 13 \cdot 5 \\ 50-99 & 30 & 18 \cdot 4 \\ 100-199 & 46 & 28 \cdot 2 \\ 200-299 & 30 & 18 \cdot 4 \\ 300-499 & 24 & 14 \cdot 7 \\ \text { Over } 499 & 11 & 6 \cdot 8\end{array}$


Very few were exactly $100 \mathrm{LD}_{50}$ and only $47 \%$ lay between 50 and $200 \mathrm{LD}_{50}$. This is due partly to an inherent lack of precision in the method of assay of the seed virus, but mainly to variations in the behaviour of virus during storage. Because of this variability, workers are forced to regard a range of virus doses as giving comparable tests, and $50-300 \mathrm{LD}_{50}$ is commonly accepted. It is, however difficult to believe that a sixfold increase in virus dose does not affect the number of mice protected. Using this type of technique, however, the only alternative would be very many repetitions of the tests.

Discontinuity in the mortality ratio. Mortality ratios give a very discontinuous scale with, for example, only 5 points between 0 and $100 \%$ mortality with groups of six mice. This means that relatively wide safety limits must be set.

Loss of available information. In adopting mortality ratios we are discarding available information, namely the number of days between the inoculation and death of each mouse.

\section{$(1 \cdot 3)$ Summary of the need for a new approach}

In summary, therefore, the objections to the time-honoured methods for survey neutralization tests are that they force one to regard as comparable the responses to widely different virus doses and, because of their lack of precision, these methods require wide safety limits and therefore many repeat tests.

\section{(2) THE METHOD USING SURVIVAL TIME}

\section{(2.1) The basis}

The method is based on the finding of Gard (1940) that there is an approximate rectilinear relation between the log dose of virus administered to a group of mice and the mean of the reciprocals of the number of days each mouse survives. Similar relations have been used in toxicology and pharmacology by Ipsen \& Toft (1946), Box \& Cullumbine (1947) and Perry (1950); and in virology by Brownlee \& Hamre (1951), and by Crocker \& Bennett (1955).

In virology the underlying mechanism is presumably that death occurs when a certain concentration of virus in the animal's brain is reached. This critical concentration is reached more slowly when the dose administered is small than when it is large. The time necessary for the virus to reach the critical concentration depends on the multiplication-rate of the virus, and the concentration which causes death depends on the susceptibility of the test animal.

In assays based on quantal responses, each animal contributes only a positive or negative reading (usually death or survival) to the total information obtained. The use of a continuous variate such as the time response, however, means that each animal contributes a numerical estimate of the amount of infective virus inoculated into it. The information obtained per animal is therefore greater so that, employing the same number of animals, greater accuracy can be achieved than by the use of quantal responses.

The choice of continuous variate is important. Gard (1940) used reciprocals of survival times related to log dose, as did Brownlee \& Hamre (1951) and Crocker \& 
Bennett (1955). Toxicologists, on the other hand, have used reciprocals of time related to dose (Perry, 1950) and log time related to the reciprocals of the squareroot of time (Ipsen \& Toft, 1946).

As was shown by Gard (1940) and by Brownlee \& Hamre (1951), the main benefit of the reciprocal transformation is that it tends to equalize the variance of responses over the whole range of doses, while the use of untransformed time gives a correlation between the degree of response and its variance.

The survival time index $(Y)$ adopted is therefore that of Gard (1940) with different interpretation for survivors

$$
Y=\frac{1000}{K} \sum_{i=1}^{K} \frac{1}{t_{i}}
$$

where $K$ is the number of mice in the group, and $t_{i}$ the number of days survived by the $i$ th mouse.

As is conventional (see above), mice dying before the 4th day are disregarded, and mice paralysed on the day of discard are regarded as having died on that day. Survivors are regarded as dying on the 42nd day $(1000 / t=23 \cdot 8)$ (for reasons see p. 232). The minimum value of $Y$ is therefore $23 \cdot 8$ and is obtained when the whole group survives.

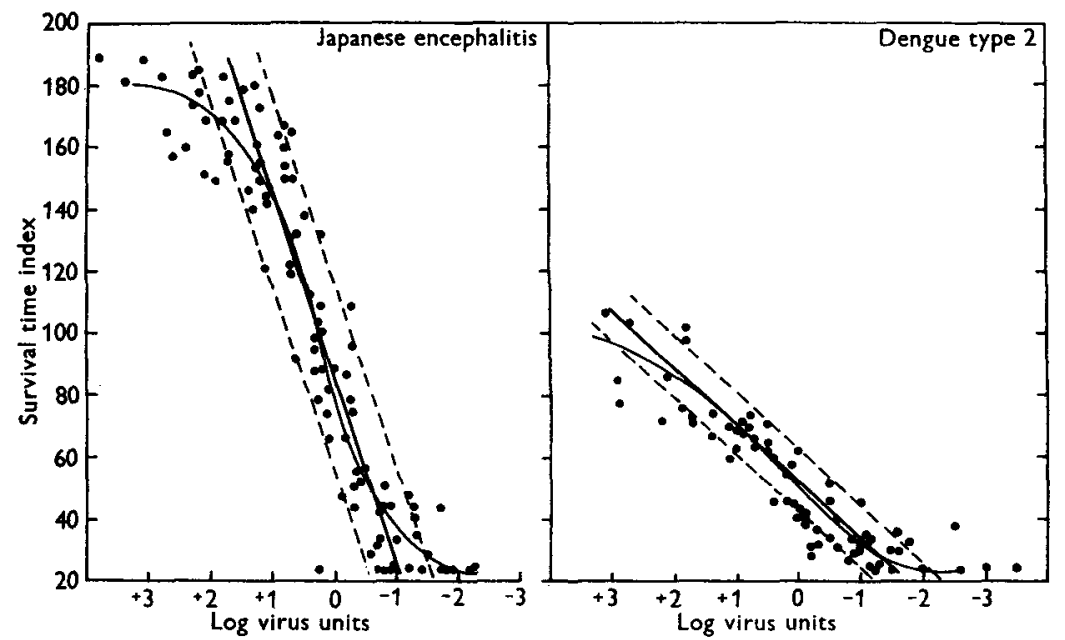

Fig. 1. Survival time indices from a number of titrations of Japanese encephalitis and dengue-2 virus plotted against $\log$ dose of virus where 0 units corresponds to $1 L_{50}$.

Fig. 1 shows the result obtained by plotting $Y$ in a number of titrations against $\log$ dose which has been adjusted in each titration so that 0 units $=1 \mathrm{LD}_{50}$. A rapidly multiplying virus (JE) is contrasted with the slow-growing dengue-2. It can be seen that the relation is truly sigmoid, there being a minimum survival time beyond which increased doses have no effect on $Y$ (e.g. 4-5 days with JE giving $Y=200-250$ ) and, at the other end, dilution beyond the end-point continues to give $Y=23.8$ as all mice survive. It can be seen, however, that for practical purposes the relation can be regarded as rectilinear over the region of the curve which it is proposed to use. As the $\mathrm{LD}_{50}$ estimates in the individual titrations 
used in plotting the points in Fig. 1 are known to have $95 \%$ confidence limits averaging about \pm 0.5 on the logarithmic scale, some of the scatter is due to this imprecision and the linear relation is probably even better than Fig. 1 suggeststhis range of $\pm 0.5 \mathrm{log}$ units is shown on either side of the straight line and it is seen that practically all points fall within this range.

Within certain limits therefore there is a rectilinear relation between the survival time index and the log dose of virus inoculated.

\section{$(2 \cdot 2)$ An example of the application of this method}

Seed virus was prepared as a $20 \%(\mathrm{w} / \mathrm{v})$ suspension of brains of moribund mice in iced inactivated normal rabbit serum (NRS). The suspension was centrifuged at 3000 r.p.m. for $10 \mathrm{~min}$. in the cold and the supernatant sealed in glass ampoules, and stored in a dry ice cabinet at about $-70^{\circ} \mathrm{C}$. Dengue seed virus was prepared from suckling mouse brains. JE and FNYF seed virus was prepared in 5-6 g. mice. Lyophilized yellow fever vaccine was used as a source of $17 \mathrm{D}$ virus. Soon after placing the seed in the dry ice, the contents of two ampoules were thawed, diluted to $10 \%$ brain either in fresh guinea-pig serum (GPS-for dengue) or in $10 \%$ inactivated NRS in saline (RSS - for JE, etc.), incubated for the same period as in the test (see below) at $37^{\circ} \mathrm{C}$. (30 min. for $\mathrm{JE}$, etc., $2 \mathrm{hr}$. for dengue) and then diluted in steps at intervals of 0.5 in the logarithmic scale, with each of which six mice were inoculated intracerebrally (6-10 g. mice for dengue, 10-15 g. mice for JE, YF).

The mice were observed for 14 days for JE and FNYF, or 21 days in the tests with dengue and $17 \mathrm{D}$. Deaths before the 4 th day were regarded as traumatic and mice so dying were ignored. Mice paralysed on the 14th or 21 st days respectively were regarded as dying on that day for purposes of calculation. If there was more than one traumatic death in a group of six mice, the whole group was disregarded. Mice surviving at the 14th or 21 st days respectively were considered to die 42 days after inoculation for purposes of calculation (see p. 232). Survival time indices ( $Y$ ) were calculated for each group of mice and plotted against the corresponding log dose of virus. The resulting curve, which is of the type depicted in Fig. 1, shows the relation between survival-time index and dilution for the seed virus.

The test. A dose of virus, $C$, is chosen within the upper range of the linear portion of the titration curve so that neutralization will give values on the linear portion of the curve. A series of doses of virus logarithmically spaced above and below the dilution $C$ (usually $\sqrt{ } 10$-fold; but 10 -fold, etc., dilutions can be used) are prepared in RSS (JE, YF) or GPS (dengue). The dilutions are kept in an ice-bath and protected from light for the duration of the experiment to minimize inactivation of the virus pool dúring the course of the experiment. Two tubes of $0.25 \mathrm{ml}$. of inactivated NRS have been previously prepared for each virus dilution in the titration, and one tube of $0.25 \mathrm{ml}$. of each serum to be tested have been set out. Starting with the highest virus dilution in the titration, $0.25 \mathrm{ml}$. of it is added to one tube of NRS, and, after mixing, the tube is placed in the $37^{\circ} \mathrm{C}$. water-bath. A similar volume of the next lower virus dilution is added to another tube of NRS, and so on as quickly as possible to the end of the titration. $0.25 \mathrm{ml}$. of the dose $C$ 
of virus is then added to each serum sample to be tested in turn, at the rate of one each minute. The mixtures are placed in the water-bath as before. After all the sera have been dealt with, $0.25 \mathrm{ml}$. of each of the virus dilutions of the titration

Table 1. A specimen calculation of $Y_{0}$ and $Y_{L}$ in an actual test

Virus: Dengue-2

Log virus Survival dilutions

$(x)$

\begin{tabular}{|c|c|c|}
\hline & $\begin{array}{l}\text { Log virus } \\
\text { dilutions }\end{array}$ & $\begin{array}{l}\text { Survival } \\
\text { time inde }\end{array}$ \\
\hline & $(x)$ & $(y)$ \\
\hline 1 & $-1 \cdot 5$ & $101 \cdot 4$ \\
\hline 2 & $-1 \cdot 5$ & $110 \cdot 7$ \\
\hline 3 & $-2 \cdot 0$ & $92 \cdot 8$ \\
\hline 4 & $-2 \cdot 0$ & $93 \cdot 4$ \\
\hline 5 & $-2 \cdot 5$ & $83 \cdot 3$ \\
\hline 6 & $-2 \cdot 5$ & $76 \cdot 1$ \\
\hline 7 & $-\mathbf{3} \cdot 0$ & $77 \cdot 1$ \\
\hline 8 & $-3 \cdot 0$ & $89 \cdot 2$ \\
\hline 9 & $-3 \cdot 5$ & $71 \cdot 8$ \\
\hline 10 & $-\mathbf{3 . 5}$ & 68.9 \\
\hline 11 & $-4 \cdot 0$ & $73 \cdot 7$ \\
\hline 12 & $-4 \cdot 0$ & $65 \cdot 8$ \\
\hline 13 & $-4 \cdot 5$ & 38.2 \\
\hline 14 & -4.5 & $45 \cdot 3$ \\
\hline 15 & $-5 \cdot 0$ & $35 \cdot 5$ \\
\hline 16 & $-5 \cdot 0$ & $38 \cdot 5$ \\
\hline & $2 \cdot 0$ & $1161 \cdot 7$ \\
\hline
\end{tabular}

Date 3. v. 56

Neut. no. 86

$$
\begin{aligned}
C=x_{0} & =-3 \cdot 0 \\
n & =16 \\
\bar{x} & =\frac{\Sigma x}{n}=-3 \cdot 25 \\
\bar{y} & =\frac{\Sigma y}{n}=72 \cdot 60625 \\
\Sigma x^{2} & =190 \cdot 0 \\
\Sigma y^{2} & =92420 \cdot 61 \\
\Sigma x y & =-3384 \cdot 15 \\
\Sigma(x-\bar{x})^{2} & =\Sigma x^{2}-\frac{(\Sigma x)^{2}}{n} \\
& =190 \cdot 0-169 \cdot 0=21 \cdot 0 \\
\Sigma(y-\bar{y})^{2} & =\Sigma y^{2}-\frac{(\Sigma y)^{2}}{n} \\
& =92420 \cdot 61-84346 \cdot 68=8073 \cdot 93 \\
\Sigma(x-\bar{x})(y-\bar{y}) & =\Sigma x y-(\Sigma x) \bar{y} \\
& =-3384 \cdot 15-(-3775 \cdot 525)=391 \cdot 375 \\
b & =\frac{\Sigma(x-\bar{x})(y-\bar{y})}{\Sigma(x-\bar{x})^{2}}=\frac{391 \cdot 375}{21 \cdot 0}=18 \cdot 637 \\
b^{2} & =347 \cdot 338 \\
& \\
\Sigma &
\end{aligned}
$$

Equation of the regression line

$$
\begin{aligned}
y & =\bar{y}+b(x-\bar{x}) \\
& =72 \cdot 606+18 \cdot 637(x-(-3 \cdot 25)) \\
\text { i.e. } y & =133 \cdot 176+18 \cdot 637 x \\
\therefore Y_{0} & =133 \cdot 176+18 \cdot 637 x_{0}=77 \cdot 265
\end{aligned}
$$

Regression analysis

$$
\begin{array}{lccc} 
& \text { D.F. } & \text { Sum of squares } & \text { Mean squares } \\
\text { Total } & n-1=15 & \Sigma(y-\bar{y})^{2}=8073 \cdot 93 & - \\
\text { Due to regression } & 1 & b^{2} \Sigma(x-\bar{x})^{2}=7294 \cdot 098 & - \\
\text { Residual } & n-2=14 & 779 \cdot 832 & s^{2}=\frac{\overline{779 \cdot 832}}{14}=55 \cdot 70229
\end{array}
$$

Variance of $Y_{0}$

$$
s_{0}^{2}=\frac{s^{2}}{n}+\frac{\left(x_{0}-\bar{x}\right)^{2} s^{2}}{\Sigma(x-\bar{x})^{2}}=\frac{55 \cdot 70229}{16}+\frac{(0 \cdot 25)^{2} \times 55 \cdot 70229}{21 \cdot 0}=3 \cdot 647174 \text {. }
$$

Limit $Y_{L}=Y_{0}-t_{n \rightarrow 2} \sqrt{ }\left(s^{2}+s_{0}^{2}\right)$

$$
=77 \cdot 265-1 \cdot 761 \sqrt{ }(55 \cdot 702+3 \cdot 647)=77 \cdot 265-13 \cdot 566 \text {, }
$$

i.e. $Y_{0}=77 \cdot 265$. $Y_{L}=63 \cdot 699$. 
is added in turn to tubes of $0.25 \mathrm{ml}$. of NRS as at the beginning of the experiment and placed in the water-bath. This forms the end titration. After the period of incubation ( $30 \mathrm{~min}$. for JE, YF; $2 \mathrm{hr}$. for dengue) the tubes are removed from the water-bath in the same order and at the same rate ( 1 per min.) and the mixtures each inoculated intracerebrally $(0.03 \mathrm{ml}$.) into six mice of the same weight range (6-10 g. for dengue, 6-10, or 10-15 g. for JE, YF).

Calculation of results. Survival-time indices $(Y)$ are calculated for all groups of mice. By conventional means (see Table 1) the regression line of $Y$ on log dose $(x)$ is calculated for the pooled observations of the beginning and end titrations. The regression analysis is calculated and the residual variance, $s^{2}$, about the regression line is determined. The value $x_{0}$ (equivalent on the log dilution scale to the virus dose $C$ ) is then substituted in this titration regression equation to obtain the corresponding survival-time index, $Y_{0}$.

Now suppose that a test serum, using six animals and the same virus dose $C$, gives a survival-time index (S.T.I.) of $Y_{t}$ and we wish to determine whether $Y_{t}$ differs significantly from $Y_{0}$. The variance of $Y_{0}$ is

$$
\text { var. } Y_{0}=s_{0}^{2}=\frac{s^{2}}{n}+\frac{\left(x_{0}-\bar{x}\right)^{2} s^{2}}{\sum_{1}^{n}(x-\bar{x})^{2}},
$$

where $n$ is the total number of groups of six mice used to determine the regression equation.

If we assume the test serum to have parallel regression with the titration regression, then the variance of $Y_{t}$ may be estimated as $s^{2}$.

For significance at the $10 \%$ level, the difference between $Y_{0}$ and $Y_{t}$ must not be less than $t_{n-2} \sqrt{ }\left(s_{0}^{2}+s^{2}\right)$, where $t_{n-2}$ is the value of ' $t$ ' corresponding to the $10 \%$ level of significance with $(n-2)$ degrees of freedom. The limit

$$
Y_{L}=Y_{0}-t_{n-2} \sqrt{ }\left(s_{0}^{2}+s^{2}\right)
$$

is then calculated. The survival-time indices of the unknown sera are then compared as described below, with $Y_{0}$ and the limit $Y_{L}$.

A typical calculation of the regression equation and the estimation of $Y_{0}$ and $Y_{L}$ is demonstrated in Table 1 . Using a machine the whole calculation takes only about $30 \mathrm{~min}$. The calculation in Table 1 is graphically presented in Fig. 2.

Interpretation. This is based on the use of a ' $t$ ' test to compare two means namely $Y_{0}$ (the control) and $Y_{t}$ (the unknown serum). The observation $Y_{t}$ is an estimate of the 'true' value of the s.T.I. of an unknown serum at the test dose of virus, $C$. Similarly, $Y_{0}$ is an estimate of the population mean of the control at the same dose. If these two population values are in fact equal then the observed difference between $Y_{t}$ and $Y_{0}$ should not exceed the value $t_{n-2} \sqrt{ }\left(s_{0}^{2}+s^{2}\right)$ more than 1 in 10 times. Consequently, if we observe that

$$
Y_{t} \gtrless Y_{L}=Y_{0}-t_{n-2} \sqrt{ }\left(s_{0}^{2}+s^{2}\right),
$$

then we are prepared to conclude that the unknown differs from the control. If, in fact, the true index of the unknown serum is greater than or equal to the control then such an observed value of $Y_{t}$ cannot be expected more frequently than 1 in 20 . 
An observation $Y_{l}$ can fall into any of the following categories:

(a) $Y_{t}$ is significantly less than the control $Y_{0}$, i.e.

$$
Y_{t} \leqslant Y_{L}=Y_{0}-t_{n-2} \sqrt{ }\left(s_{0}^{2}+s^{2}\right) \text {. }
$$

(b) $Y_{t}$ is numerically equal to or less than $Y_{0}$ but not significantly so, i.e.

$$
Y_{L}<Y_{t} \gtrless Y_{0} \text {. }
$$

(c) $Y_{t}$ is numerically greater than $Y_{0}$ but not significantly so, i.e.

$$
Y_{0}<Y_{t}<Y_{u} \text {. }
$$

(d) $Y_{t}$ is significantly greater than $Y_{0}$,

i.e.

$$
Y_{t} \geqslant Y_{u}=Y_{0}+t_{n-2} \sqrt{ }\left(s_{0}^{2}+s^{2}\right) .
$$

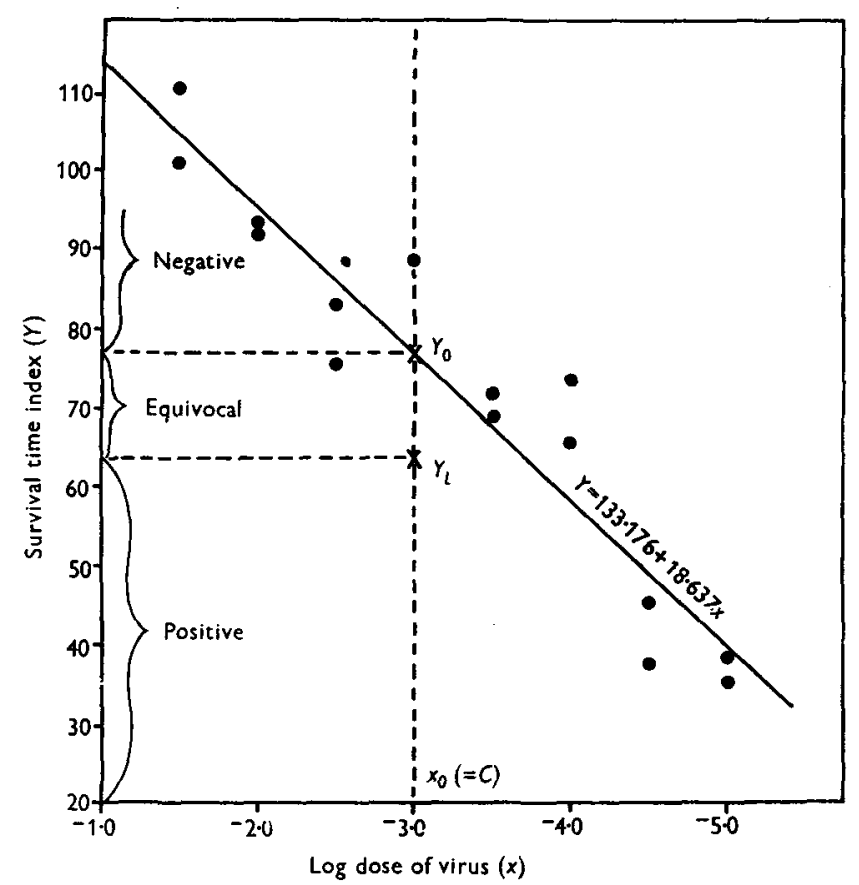

Fig. 2. Graphical representation of the sample calculation in Table 1.

An observation in category $(a)$ is designated a positive result and such a test is not repeated. An observation in either category $(b)$ or $(c)$ is of unknown meaning since its true value of $\left(Y_{0}-Y_{t}\right)$ may be positive. But observations in category (c) are less likely to have a positive true value of $\left(Y_{0}-Y_{t}\right)$ than those in $(b)$. Hence, because it is essential to economize in mice, only observations in category (b) are normally repeated and are called equivocal $( \pm)$. The observations in categories $(c)$ and $(d)$ are together called negative results and are not repeated although it is recognized that there is some possibility of category $(c)$ observations being truly positive. 
The three classes:

$$
\begin{array}{lll}
\text { Positives } \quad: Y_{l} \leqslant Y_{L} & :+ \\
\text { Equivocals }: Y_{L}<Y_{l} \leqslant Y_{0} & : \pm \\
\text { "Negatives": } Y_{0}<Y_{t} & :-
\end{array}
$$

are the approximate counterparts of the classes used in the mortality-ratio method where they are defined by arbitrary ratios (see page 225).

\section{(2·3) Difficulties}

Preliminary orientation of seed virus. As can be seen in Fig. 1 about $100 \mathrm{LD}_{50}$ $(=C)$ is the virus dose of choice, but if it is less than this there is usually little loss of information except when it falls below about $30 \mathrm{LD}_{50}$. When $100 \mathrm{LD}_{50}$ is exceeded, and the curved portion of the line is entered, the effect is to reduce the slope of the regression line and to increase the residual variance. Both these factors tend to reduce the limit $Y_{L}$ and thereby increase the number of equivocals. There is therefore wastage of mice by increase in the equivocal results but no loss of confidence in the positives.

Method of calculation of the regression line. Calculation of the common regression line of the pairs of titration points determined at the beginning and end of the test, adequately takes into consideration the behaviour of the virus during the procedure and the degree of the experimental error. Thus a badly performed test is allowed for by a great increase in the number of equivocal results and a consequent loss of information, but even in such a test significant positive results could still be accepted with confidence.

Survivors. The main difficulty arises in deciding how to score for survivors. This was avoided by Perry (1950) and by Crocker \& Bennett (1955) by ensuring that all, or nearly all, the animals died. This is not a readily acceptable manoeuvre in virology where sera may contain sufficient antibody to reduce the strength of the virus dose by 100 - or even 10,000-fold. Such a proviso would, moreover, greatly narrow the range of virus doses capable of giving a usable test and, as has been shown above, the intended dose of virus in a test is frequently very different from that actually achieved. Gard (1940) regarded survivors as living forever so that the reciprocal became zero.

Finney (1952), in a short discussion of this problem based on an experiment where survivors were few, found that he could regard survivors as dying 2 days after completion of the test (16th day). Finney's approximation gives a better fit to the regression than Gard's, but, in this instance, this minimization of the residual variance about the regression line may be a spurious criterion. We suspect that both Finney's and Gard's estimates are often too extreme, and we have therefore preferred to regard survivors as dying 42 days after inoculation. This is twice 21 days which is the longer period of observation of inoculated mice used in these tests, and therefore corresponds to linear interpolation between the reciprocals of infinity and the maximum observation time. The results of a single test computed for the different values for survivors is shown in Table 2, and it can be seen that although the equivocal region was smallest by Finney's approximation, the positive 
region was also smallest. The largest regions were given by Gard's approximation. Doubtless more accurate estimates could be derived by using the information known about the non-survivors in a particular group of mice, but there are difficulties in generalizing about the form of the distribution of survival times in a group of mice. Use of the arbitrary value of 42 days (or those proposed by Gard and Finney) makes the computation simpler which is highly desirable in the present context.

Table 2. Comparison of the use of different approximations in the calculation of the survival-time index where there are survivors

\begin{tabular}{|c|c|c|c|c|}
\hline Values for survivors & $Y_{0}$ & $Y_{L}$ & $\begin{array}{c}\text { Equivocal } \\
\text { region } \\
\left(Y_{0}-Y_{L}\right)\end{array}$ & $\begin{array}{c}\text { Positive region } \\
\left(Y_{L}-\text { minimum S.T.I. }\right)\end{array}$ \\
\hline $\begin{array}{l}\text { Finney }(1952) \quad 16 \text { days } \\
\text { Minimum s.T.I. }=62.5\end{array}$ & $142 \cdot 19$ & $111 \cdot 15$ & $31 \cdot 04$ & $48 \cdot 65$ \\
\hline $\begin{array}{l}\text { This paper } 42 \text { days } \\
\text { Minimum s.T.I. }=23.8\end{array}$ & $144 \cdot 39$ & 96.91 & $47 \cdot 48$ & $73 \cdot 11$ \\
\hline $\begin{array}{l}\text { Gard }(1940) \\
\quad \text { Minimum s.T.I. }=0.0\end{array}$ & $145 \cdot 68$ & $87 \cdot 70$ & 57.98 & $87 \cdot 70$ \\
\hline
\end{tabular}

Ways of diminishing the equivocal region

(a) Spacing of titration dilutions. Twofold and $\sqrt{ }$ tenfold $\left(\right.$ half- $\left.\log _{10}\right)$ dilutions have been used and compared. The latter cover a wider range for the same number of mice and appear to give better results.

(b) Error due to imprecision in the determination of the slope. The variance of $Y_{0}$ is

$$
\text { var. } \begin{aligned}
Y_{0} & =\operatorname{var} \bar{y}+\left(x_{0}-\bar{x}\right)^{2} \operatorname{var} b \\
& =s^{2} / n+\frac{\left(x_{0}-\bar{x}\right)^{2} s^{2}}{\Sigma(x-\bar{x})^{2}} \quad \text { (see Table 1). }
\end{aligned}
$$

Clearly this is a minimum when $x_{0}=\bar{x}$, that is when dose $C$ is the mid-point of the series of virus dilutions. When this is so, the variance of $Y_{0}$ reduces to $s^{2} / n$ and is unaffected by the variance of the slope of the regression line. The difference between the limit $Y_{L}$ and $Y_{0}$ is then also a minimum.

The question of the best method of preparing the virus dilutions now arises. This can be done in two main ways:

(i) A pool of virus is prepared so as to contain the test dose of virus, $C$. Dilutions are prepared from this pool for titration, and, after incubation with control serum, each dilution is inoculated into mice. Amounts are taken from the pool and added to the unknown sera throughout the test. Finally at the end of the test, the pool is diluted and inoculated as in the beginning titration. This has the advantage that the actual virus pool used is diluted at the beginning and end of the experiment and it is the changes in this pool which are measured. On the other hand, this places $x_{0}$ (corresponding to dose $C$ ) at one end of the titration series of log doses, and thereby increases the variance of $Y_{0}$.

(ii) Alternatively, a series of dilutions can be prepared with the dose $C$ as its mid-point. The dilutions are then inoculated at the beginning of the test after 
incubation with control serum, the dose $C$ is added to the unknown sera, and the dilutions again incubated and inoculated at the end of the test. This reduces the variance of $Y_{0}$ by eliminating any contribution due to the variance of the slopes, but it means that changes are being measured in a whole series of dilutions which may be dying off at different rates. This, in turn, may increase the residual variance, $s^{2}$, about the regression line. Hence there seem to be two conflicting requirements, but, in practice, with a good test having a suitable range of titration doses, the contribution to the variance of $Y_{0}$ from errors in determining the slope is relatively small, and method (i) is preferred.

(c) Use of a mean slope. Crocker \& Bennett (1955) determined a mean slope for a large series of observations with meningopneumonitis virus in the chick embryo and were then able to use this in estimating relative potency by parallel line assay. An attempt was made to do this with the data reported here by estimating the common slope of many regressions for a particular virus. However, the precision of this pooled estimate of slope was not materially greater than that obtained from an individual regression because of differences (although they were non-significant) between the values of the slopes forming the pooled estimate. Hence no advantage was achieved and, moreover, it would mean that to apply the method to another virus or in another laboratory would require lengthy standardization, thus defeating the simplicity of the present method.

(d) Increase in numbers of animals and groups. For convenience in computation, a fixed group size (for example, six animals) is adopted throughout the experiment. Increasing the number of mice per group beyond six would lead to some small reduction in the residual variance about the regression line and would slightly reduce the proportion of equivocal results. But it is doubtful whether the cost of such increases in group size is justified, since equivocal tests can be repeated and there is little virtue in establishing positives with an unduly high level of significance.

Increases in the number of groups of mice in the titrations reduces the equivocal region between $Y_{0}$ and limit $Y_{L}$. This is due not only to the increase in $n$ and reduction in $t_{n-2}$, but also to the increase in $\Sigma(x-\bar{x})^{2}$. This latter quantity might also be increased by choosing the titration doses at the extreme ends of the titration dose range. But a group is only of value if it is within the range where the linear relationship holds good; more virus dilutions at the curved ends of the regression line are useless. It is often found necessary to discard one or more groups at one or other end of the titration because it has extended too far. For these reasons it is felt that even spacing on the logarithmic dose scale is likely to be less wasteful, and that about six to eight groups per titration (i.e. $n=12$ to 16 ) is suitable.

Interference. Where concentrated virus suspensions are used, usually because there has been fall in titre of stored seed virus, there may be a considerable proportion of dead virus present. The dead virus may 'interfere' in the lowest dilutions so that the s.T.I./log dose curve bends downwards at the highest concentrations of virus. Interference is, of course, to be avoided by using only high titred seed : but it arises unexpectedly from time to time, and such tests are still usable with care. The log dose giving the maximum value of $Y$ obtained is taken as the highest dose in the 
computation as this dilution is beyond the range of effect of the interfering virus. The phenomenon has been observed only with the dengue viruses.

\subsection{Relation of the survival-time index method to one of the older methods}

Table 3 shows the result obtained in three different tests which were performed on different groups of unknown sera. In test no. 39 where the dose of virus $(C)$ was $50 \mathrm{LD}_{50}$, there were fewer positives and negatives by the s.T.I. method than by

Table 3. Comparison of analysis by survival-time index with that by mortality ratio in tests with different amounts of virus. Number of sera which gave positive, equivocal or negative results

\begin{tabular}{|c|c|c|c|c|c|c|c|c|}
\hline \multirow{2}{*}{$\begin{array}{l}\text { Doses of virus } \\
\qquad(C)\end{array}$} & \multicolumn{7}{|c|}{ Mortality ratios (Deaths/Total) } & \multirow{2}{*}{$\begin{array}{r}\text { Total } \\
\text { results } \\
\text { by s.T.I }\end{array}$} \\
\hline & $0 / 6$ & $1 / 6$ & $2 / 6$ & $3 / 6$ & $4 / 6$ & $5 / 6$ & $6 / 6$ & \\
\hline $\begin{array}{l}50 \mathrm{LD}_{50} \text { (test } \\
\text { no. } 39 \text { ) }\end{array}$ & $\begin{array}{r}26 \\
. \\
.\end{array}$ & $\begin{array}{r}10 \\
8 \\
.\end{array}$ & $\begin{array}{r}1 \\
11 \\
\cdot\end{array}$ & $\begin{array}{l}\dot{7} \\
2\end{array}$ & $\dot{2}$ & $\begin{array}{l}\dot{3} \\
1\end{array}$ & i & $\begin{array}{l}37+ \\
32 \pm \\
12-\end{array}$ \\
\hline $\begin{array}{l}\text { Total results by } \\
\text { mortality ratio }\end{array}$ & \multicolumn{2}{|c|}{$44+$} & \multicolumn{2}{|c|}{$21 \pm$} & & $16-$ & & \\
\hline $\begin{array}{l}100 \mathrm{LD}_{50} \text { (test } \\
\text { no. } 42 \text { ) }\end{array}$ & $\begin{array}{l}1 \\
\cdot \\
.\end{array}$ & $\begin{array}{r}4 \\
.\end{array}$ & $\begin{array}{l}3 \\
. \\
\text {. }\end{array}$ & $\begin{array}{l}2 \\
. \\
.\end{array}$ & $\begin{array}{l}5 \\
. \\
.\end{array}$ & $\dot{\cdot} \cdot$ & $\begin{array}{r}27 \\
29\end{array}$ & $\begin{array}{l}15+ \\
27 \pm \\
29-\end{array}$ \\
\hline $\begin{array}{l}\text { Total results by } \\
\text { mortality ratio }\end{array}$ & \multicolumn{2}{|c|}{$5+$} & \multicolumn{2}{|c|}{$5 \pm$} & & $61-$ & & \\
\hline $\begin{array}{l}300 \mathrm{LD}_{50} \text { (test } \\
\text { no. } 30 \text { ) }\end{array}$ & $\dot{.}$ & $\begin{array}{l}3 \\
\text {. } \\
\text {. }\end{array}$ & $\begin{array}{l}3 \\
\text {. } \\
\text {. }\end{array}$ & $\begin{array}{l}3 \\
\text {. } \\
\text {. }\end{array}$ & $\begin{array}{l}\mathbf{3} \\
\cdot \\
.\end{array}$ & $\begin{array}{l}7 \\
. \\
\text {. }\end{array}$ & $\begin{array}{r}15 \\
5\end{array}$ & $\begin{array}{r}19+ \\
15 \pm \\
5-\end{array}$ \\
\hline $\begin{array}{l}\text { Total results by } \\
\text { mortality ratio }\end{array}$ & & & & & & $30-$ & & \\
\hline
\end{tabular}

mortality ratio (as interpreted by Smithburn et al., 1954b), and it can be seen that the disagreements all fell into the equivocal group which is entirely unobjectionable as these tests would be repeated. In test no. 42 , where there was a virus dose of $100 \mathrm{LD}_{50}$, it can be seen that three times as many positives were detected by s.T.I. as by mortality ratio (M.R.) and that about half the negatives by M.R. required repetition by the S.T.I. test. All five of the negatives by M.R. which were revealed to be positive were retested at least twice by the new method and remained consistently positive. In test no. 30, where there was a virus dose of approximately $300 \mathrm{LD}_{50}$, all groups showing a mortality ratio less than $6 / 6$ were found by S.T.I. to be indicative of significant neutralization and nineteen positives were detected as compared with three by M.R. All the equivocals and ten of the negatives by M.R. were found to have antibody. Twelve of the sera, which were negative or equivocal by M.R., were retested at least once and found to be consistently positive by s.T.I. As was expected, 
increasing numbers of $\mathrm{LD}_{50}$ 's in the dose $(C)$ reveal fewer positive sera if interpreted by mortality ratio alone because although sera may be capable of neutralizing $50 \mathrm{LD}_{50}$, many of them cannot sufficiently neutralize $300 \mathrm{LD}_{50}$. It appears from this table and from the general pattern of results that the sensitivity of the new method is approximately equivalent to a test by the mortality-ratio method using about $50 \mathrm{LD}_{50}$ of virus and the arbitrary mortality ratios defined by Smithburn et al. (1954b).

Another way of assessing the sensitivity of the test is to substitute $Y_{L}$ for $Y$ in the equation to the regression line for each test and thus obtain the log dose of virus $x_{L}$ corresponding to $Y_{L} \cdot\left(x_{L}-x_{0}\right)$ then gives the $\log$ minimum number of $\mathrm{LD}_{50}$, which must be neutralized in that test to give a positive result. When this was done in fifty-seven tests, the range of values for $\left(x_{L}-x_{0}\right)$ was $0.5-4.8$ log but its mean was $1.76 \mathrm{log}$ and the distribution had a standard deviation of $\pm 1.003 \mathrm{log}$. This corresponds to $57 \mathrm{LD}_{50}$ and means that the average sensitivity of the test is of the order of $50 \mathrm{LD}_{50}$, but while in some tests the neutralization of about $5 \mathrm{LD}_{50}$ is significant, in others only sera which neutralize about $10,000 \mathrm{LD}_{50}$ will show up as positive. This of course depends on the quality of the test and does not affect the reliability of results-a positive remains significant, but in a bad test most of the potential positives are recorded equivocal and have to be repeated.

\subsection{Consistency of results with the survival-time index method}

The method has now been used in the analysis of about eighty neutralization tests involving about 4500 sera from man and both domestic and wild animals. Tests have included five viruses: Japanese encephalitis (Nakayama strain); dengue-1 (Hawaii

Table 4. Results of once-repeated determinations on 229 sera

\begin{tabular}{lrrrrr}
\multirow{3}{*}{ 2nd test } & & \multicolumn{4}{c}{ 1st test } \\
& + & 111 & 13 & - & Total \\
& \pm & 28 & 28 & 13 & 125 \\
Total & - & 5 & 26 & 4 & 35 \\
& & 144 & 67 & 18 & 229
\end{tabular}

and CHIA stains); dengue-2 (New Guinea ' $C$ '); French neurotropic and $17 \mathrm{D}$ yellow fever viruses. Doses $(C)$ of virus have ranged from less than 10 to about $1000 \mathrm{LD}_{50}$. Table 4 shows the results of the first 229 sera on which a test had been repeated once only.

Of 144 originally scored as positive only five $(3.5 \%)$ were subsequently recorded negative, and of eighteen original negatives only one (5.6\%) was given as positive in the second test. The average risk of marking a serum positive if it is in fact truly negative is claimed to be less than $5 \%$ (see above). In the results quoted in Table 4 we do not of course know with certainty which sera are truly positive or negative, but the agreement between the lst and 2nd tests is clearly satisfactory and provides rough confirmation of the estimated risk of misclassification. 
A similar analysis including tests (615 observations), which were repeated more than once, showed that the total incidence of sign reversal (i.e. repeat observations negative or positive where lst observation was positive or negative respectively) was only $2 \cdot 6 \%$.

The above work which has been used to illustrate and evaluate this technique, consists of serum surveys of man and animals in Malaya by one of us (C.E.G.S.). This paper is designed to precede the papers describing the results of these surveys.

\section{(3) CONCLUSIONS}

The method described has therefore the following advantages:

(a) It is based on a definite and previously chosen level of significance so that any desired degree of risk may be taken. The average risk of misclassification adopted in this laboratory is estimated to be not more than $5 \%$.

(b) It gives consistent and strictly comparable results over a wide range of virus doses thus eliminating the risk of having to discard a whole test because too much or too little virus has been used.

(c) Account is automatically taken of the quality of the experiment by the method of calculation.

(d) It is at least as economical of time and animals as other methods.

(e) The calculations required are simple and easily understood with practice.

\section{(4) SUMMARY}

An analytical method based on survival-time response is described for use in survey neutralization tests with the neurotropic viruses in mice. The method is simple and has been shown to give consistent and comparable results, which enable tests which have been carried out with different doses of virus to be compared.

\section{REFERENCES}

Box, G. E. P. \& Cullumbine, H. (1947). Relationships between survival time and dosage with certain toxic agents. Brit. J. Pharmacol. 2, 27.

Brownlee, K. A. \& Hamre, D. (1951). Studies on chemotherapy of vaccinia virus. I. An experimental design for testing antiviral agents. J. Bact. 61, 127.

Bugher, J. C. (1948). Chapter on Yellow Fever in Diagnostic Procedures for Virus and Rickettsial Diseases, lst ed. p. 267. New York: American Public Health Association.

Crocker, T. T., \& BennetT, B. M. (1955). The slope assay for measurement of the lethal potency of meningopneumonitis virus in the chick embryo. J. Immunol. 75, 239.

FinNey, D. J. (1952). Statistical Method in Biological Assay. London: Chas. Griffin and Co.

GARD, S. (1940). Encephalomyelitis of mice. II. A method for the measurement of virus activity. J. exp. Med. 72, 69.

IPSEN, J. \& TOFT, H.-I. (1946). Biological assay of strychnine in young mice using death-time and convulsion-time as biometrical scores. Acta pharm. tox., Kbh., 2, 167.

MmLer, L. C. \& Tainter, M. L. (1944). Estimation of the ED 50 and its error by means of logarithmic-probit graph paper. Proc. Soc. exp. Biol., N.Y., 57, 261.

Perry, W. L. M. (1950). The design of toxicity tests. Spec. Rep. Ser. med. Res. Coun., Lond., no. 270.

REed, L. J. \& MUEnCH, H. (1938). A simple method of estimating fifty per cent end points. Amer. J. Hyg. 27, 493. 
SmithbURN, K. C. (1954). Neutralizing antibodies against arthropod-borne viruses in the sera of long-time residents of Malaya and Borneo. Amer. J. Hyg. 59, 157.

Smtrhburn, K. C., TAylor, R. M., Rizk, F. \& Kader, A. (1954a). Immunity to certain arthropod-borne viruses among indigenous residents of Egypt. Amer. J. trop. Med. Hyg. 3, 9.

Smithburn, K. C., Kerr, J. A. \& GatNe, P. B. (1954b). Neutralizing antibodies against certain viruses in the sera of residents of India. $J$. Immunol. 72, 248.

(MS. received for publication 30. vII. 56) 